\title{
Branches and Leaves Growth Patterns in Myricaria laxiflora Remnant Populations Are Affected by Human-altered Water Level Fluctuations
}

\section{Shoupeng Guan}

China Three Gorges University

Fang-Qing Chen ( $\nabla$ fqchen@ctgu.edu.cn )

Chemistry and Life Science College https://orcid.org/0000-0002-0724-6404

Jumei Zhou

China Three Gorges University

Yongwen Huang

China Three Gorges University

Dayong Fan

Beijing Forestry University

Research article

Keywords: Myricaria laxiflora; riparian zone; branch and leaf traits; water level fluctuation; phenotypic plasticity

Posted Date: August 24th, 2020

DOl: https://doi.org/10.21203/rs.3.rs-52211/v1

License: (c) (1) This work is licensed under a Creative Commons Attribution 4.0 International License. Read Full License 


\section{Abstract}

Background: The construction of the Three Gorges-Gezhou Dam altered the water level fluctuation pattern in the downstream habitat of the endangered species Myricaria laxiflora. This study investigated how branch and leaf growth traits of $M$. laxiflora remnant populations changed to adapt the environmental stress caused by human-altered water level fluctuations.

Results:Due to such disturbance, branch and leaf growth traits of $M$. laxiflora populations exhibited significant differences across water level conditions. The number of secondary branches, plant height, and leaf number of the plants in the upper area of the habitat were significantly higher than that in the middle and lower river bank areas. The longest secondary branch length of the plants in the upper and middle region was significantly higher than that in the lower region. The branch and leaf volume of plants in the middle region was significantly higher than that in the upper and lower region. The maximum water content of plants in the middle and lower region was significantly higher than that in the upper region. Principal component analysis showed that the branch and leaf traits of plants changed with decreasing water level toward to decreasing plant height, leaf number and the number of secondary branches, and increasing maximum water content of branch and leaves.

Conclusions: The phenotypic plasticity of $M$. laxiflora plants in branch and leaf growth traits alleviates the impacts of human-regulated water level fluctuations. However, the above ground growth of $M$. laxiflora plants distributed at the middle and lower areas of the fluctuation zone is still negatively affected.

\section{Background}

Plant growth traits are core morphological and physiological attributes that reflect the performance of plants in resource acquisition, processing and conservation, the relationship among plants, and the interaction between plant and environment (Roderick et al., 1999; Violle et al., 2007; Reich et al., 2014). Phenotypic plasticity is the ability of plant genotypes to make corresponding changes and produce different phenotypes to cope with the spatiotemporal heterogeneity (Bradshaw, 2006). Branch and leaf growth traits include leaf number, leaf area, branch length, stem height, branch dry mass, leaf dry mass, nitrogen content, stoma density, etc. (Zhou et al., 2018). Leaves and young branches are, in general, highly sensitive organs to external environmental conditions. The branch and leaf growth traits of plants in heterogeneous ecological environment often change to improve their resource acquisition and utilization efficiency. This adaptive change is beneficial for plants to maintain their normal physiological activities, growth and development, and improve the survival and competitiveness of species (BernardVerdier et al, 2012; Collins et al, 2016). The phenotypic plasticity of branch and leaf traits is commonly used as key parameters to evaluate not only the effect of environmental change on plant growth, but also the plant adaptability to environmental changes (Gleason et al., 2017; Liu et al., 2019). 
Water level may vary spatially and temporally resulting in differential fluctuations. Water-level fluctuations are important ecological processes that influence the ecological environment of riparian plant habitat (Spencer et al., 2004; Miao et al., 2017). Riparian plants have adapted to the submergenceemergence pattern brought by natural/normal water-level fluctuations and the accompanying changes in soil water content (Blom et al., 1994; Li et al., 2015; Campbell et al., 2016). Under the expected water level fluctuation pattern, although the leaf growth traits of riparian plants vary in space and time to a certain extent (Li et al., 2013; Chen and Xie, 2009), plant growth will not be severely affected as the change of branch and leaf characters is within the phenotypic plasticity (Campbell et al., 2016; Gao et al., 2017). However, plant branch and leaf growth traits and fitness might be significantly affected when the riparian environment is altered by the construction of a dam (Li et al., 2013; Dalke et al., 2018). They might increase stem height and single leaf area, and reduce leaf number to adapt the stress of increasing flooding time and depth caused by a dam (Chen et al., 2010; Smaouiet al., 2011). If the atypical fluctuations prolong and become severe, the growth of riparian plants is impaired leading to population dieback (Van der Sman and Van Tonger, 1988; Bijarchi et al., 2011).

Myricaria laxiflora (Franch.) P.Y. Zhang et Y.J. Zhang is a shrub species of the Tamaricaceae family. M. laxiflora measures 1-1.5 $\mathrm{m}$ in height. Young branches are very small and green. Racemes are terminal and measure 6-12 cm in length. Capsules are narrowly conical and measure 6-8 mm in length. Seeds measure 1-1.5 mm in length and are dispersed by the wind and river water flow (Chen and Xie, 2007; Guan et al., 2020a). M. laxiflora is mainly distributed in the riparian zone between Yichang at the Yangtze River and Yibin in the Jinsha River. The Three Gorges Reservoir Region is the core distribution region of this plant (Chen et al., 2005; Chen and Wang, 2015). The construction of the Three Gorges dam has significantly increased the water level of the reservoir and submerged the habitat of M. laxiflora, leaving only a few river islands in the downstream of the Three Gorges-Gezhouba Dam and Xiluodu-Xiangjia Dam cascade hydropower stations with M. laxiflora remnant populations (Chen and Xie, 2009; Chen and Wang, 2015). Before the construction of the Three Gorges-Gezhou Dam cascade hydropower station, $M$. laxiflora was usually completely submerged by flooding from June-August every year. When the water level gradually decreased in early September, M. laxiflora plants emerged and quickly restored their vegetative growth, and then began to flower and set fruits within a week (Chen and Xie, 2009). After the construction of the Three Gorges-Gezhou Dam cascade hydropower station, because human regulation on river discharge is conducted to fulfill the needs of flood prevention and power generation, the water level fluctuation pattern in the habitat of $M$. laxiflora remnant populations was significantly altered: the emergence time of habitats is delayed, average periods of emergence was shortened from 220 days to 190 days; the flooding retreat rapidly during the growth restart period; also, and the water level in the winter dry season dramatically decreased (Wang et al., 2018; Duan et al., 2016; Sun et al., 2007). We investigated the branch and leaf growth traits in populations across a water level condition during the growth restart period after emergence to understand the pattern of branch and leaf growth traits changing with water level gradient and the phenotypic plasticity. Based on the effect of the Three Gorges Dam construction on the pattern of water level fluctuations in the habitat of M. laxiflora remnant 
populations and the aquatic ecological environment, we discussed the subsequent effect on the above ground growth of plants.

\section{Results}

\section{Differences in branch and leaf growth traits among various water level conditions}

The branch and leaf traits of $M$. laxiflora exhibited significant differences across the water level conditions $(P<0.05)$ (Fig. 2). Plant height, the number of secondary branches, the longest secondary branch length, and leaf number all increased from the lower region to the upper region. There was a significant increase of $47.1 \%, 41.6 \%$, and $15.9 \%$ in plant height, the number of secondary branches, and leaf number of plants distributed at the upper region compared to the middle region $(P<0.05)$, and a significant increase of $60.6 \%, 59.3 \%$ and $33.7 \%$ compared to the lower region $(P<0.05)$, respectively. The longest secondary branch length of plants distributed at the upper region had not significant difference with middle region, but both of them were significantly higher than that of plants distributed at the lower region; branch and leaf volume, and the maximum branch and leaf water content initially increased and then decreased from the lower region to the upper region. Branch and leaf volume of plants distributed at middle region significantly increased by $25.9 \%$ and $29.9 \%$, respectively, compared to the upper and lower regions $(P<0.05)$. The maximum branch and leaf water content of plants did not differ significantly between middle region and upper region $(P>0.05)$, but both of them were significantly higher than lower region $(P<0.05)$.

\section{Changes in branch and leaf trait syndrome along the water level condition}

PCA showed that plant height, leaf number, and the number of secondary branches had a higher contribution to PC 1 , whereas the longest secondary branch length and branch and leaf volume had a higher contribution to PC 2 (Table 1). PC1 reflected a gradient of branch and leaf traits, from low to high values of plant height, leaf number, secondary branch number, longest secondary branch length and soil water content and high to low values of the maximum branch leaves water content. PC2 reflected a gradient of branch and leaf traits, from low to high values of branch and leaf volume, longest secondary branch length and leaf number and high to low values of secondary branch number, plant height and the maximum branch leaves water content. 
Table 1

Factor matrix of branch and leaf functional traits and their contribution to principal component

\begin{tabular}{|llll|}
\hline Index & $\begin{array}{l}\text { Principal component } \\
\mathbf{1}\end{array}$ & $\begin{array}{l}\text { Principal component } \\
\mathbf{2}\end{array}$ & Communality \\
\hline Plant height $(\mathrm{cm})$ & 0.75 & -0.28 & 0.64 \\
\hline Number of leaves & 0.75 & 0.20 & 0.60 \\
\hline Number of secondary branches & 0.68 & -0.39 & 0.62 \\
\hline Branch and leaf water content (\%) & -0.64 & -0.09 & 0.41 \\
$\begin{array}{l}\text { Longest secondary branch length } \\
(\mathrm{cm})\end{array}$ & 0.52 & 0.65 & 0.70 \\
\hline Branch and leaf volume (cm $\left.{ }^{3}\right)$ & -0.09 & 0.79 & 0.64 \\
\hline Eigenvalue & 2.29 & 1.33 & \\
\hline Contribution (\%) & 38.2 & 22.2 & \\
\hline Cumulative contribution $(\%)$ & 38.2 & 60.4 & \\
\hline
\end{tabular}

PCA ordination showed that the branch and leaf functional symptoms of plants differentiated significantly among different water level conditions (Fig. 3). Higher values of the maximum branch leaves water content appeared in the lower region compared to the upper region, which showed higher values of leaf number, plant height, and number of secondary branches. Therefore, as the water level and soil water content decreased, $M$. laxiflora shifted their growth investment towards a decrease in plant height, number of leaf and secondary branches, and an increase in the maximum branch leaves water content.

\section{Discussion}

\section{Responses in branch and leaf functional traits to the water level gradient}

Water level fluctuations are important ecological processes that influence the ecosystem in water levelfluctuating regions (Matthew et al., 2019). Under the influence of water level fluctuations, the ecological environment at the water level-fluctuating region exhibits clear spatial heterogeneity, where environmental factors including emergence period, emergence time and soil water content are significantly different across the water level conditions (Wang et al., 2018). Caused by the environmental heterogeneity, branch and leaf growth traits of riparian plants also exhibit spatial variations across the water level conditions (Spencer et al., 2004; McCoy-Sulentic et al., 2017; Duan et al., 2017). Lawson et al. (2015) investigated the relationship between growth traits in riparian plant communities and water level fluctuations. Their results showed that plant functional trait diversity was highly and positively correlated with metrics describing both flooding disturbance and patterns of water availability. 
Differences in branch and leaf growth traits due to environmental heterogeneity is phenotypic plasticity by which plants respond to and adapt to environmental changes (Munguia-Rosas et al., 2019; Lajoie and Vellend, 2018 ). Miles et al. (2017) studied the branch and leaf growth traits in riparian plants of the Colorado River and found that as the inundation gradients shifted from being frequently to less frequently inundated, high specific leaf area (SSA) and low stem specific gravity (SSG) shifted to low SSA and high SSG. In this study, the branch and leaf growth traits of $M$. laxiflora remnant populations exhibited spatial variations across the water level gradient. In the upper water level-fluctuating region that had an early emergence time and longer emergence period, it is easier for plants to produce sufficient numbers of branches and leaves. Plants in this region had the highest values in plant height, number of secondary branches, the longest secondary branch length and leaf number, but the lowest value in the maximum water content. On the contrary, in the middle and lower water level-fluctuating regions, where the emergence time was delayed, with a short emergence period and fast decline in water level, it is difficult for plants to produce leaves and branches. Plants in this region had the highest values in branch and leaf volume, and the maximum branch and leaf water content, but the lowest value in plant height, number of secondary branches, the longest secondary branch length and leaf number.

\section{The effect of changes in water level fluctuation patterns on branch and leaf functional traits}

Plants can adjust morphological and physiological traits to maximize the consistency of their phenotypes with environment and reduce the negative effects of environmental changes on plant growth and reproduction (Sultan, 2005; Ellers et al., 2010). This phenotypic plasticity enhances plant tolerance and facilitates plants to establish more diverse habitats (Sultan, 1995). Among the numerous plant traits, leaf traits are closely related to plant growth strategies and resource utilization ability by which plants adapting to environmental changes (Voesenek and Bailey-Serres, 2015). Li et al. (2018) carried out a study on Distylium chinense, a shrub plant distributed along the riverbank of the Yangtze River. Their results showed that the species could adapt to different hydrological conditions across riverbanks because of its wide plasticity in branch and leaf traits. In this study, plant height, leaf number and the secondary branch number of $M$. laxiflora were sensitive to water level fluctuations and resulting environmental changes, while other branch and leaf growth traits were less affected. Human-regulated water level fluctuations affected the changes of branch and leaf functional symptoms in M. laxiflora. Under this environmental condition, M. laxiflora showed a decrease in plant height, leaf number, and the number of secondary branches, as well as an increase in branch and leaf water content. The change of branch and leaf growth traits improve the efficiency of resource acquisition and utilization of the remnant M. laxiflora populations, and maintain its survival and growth under the extreme environmental stress.

The construction of the Three Gorges Dam altered the water level fluctuation pattern in the habitat of $M$. laxiflora remnant populations. The emergence time of the habitat was delayed from early September to later September, or even to early November, while the submergence time shifted forward from early June to Mid or late May. The entire emergence period was shortened from 200-240 days to 170-210 days (for the year of 2017-2018). At the same time as the habitat emerged, water declined more quickly; the water level in the dry season significantly decreased in the habitat to approximately $1.29 \mathrm{~m}$ (Sun et al., 2007). 
The change of water level fluctuations might affect the plant growth, propagation and seedling regeneration of the $M$. laxiflora remnant populations. An investigation on the $M$. laxiflora remnant populations by Bao et al. (2010) revealed that the remnant population structure had an extremely low ratio of young seedlings, indicating a population degradation caused by the hindered population regeneration. In our recent study on the growth and reproduction characteristics of $M$. laxiflora remnant populations, sexual reproduction, photosynthetic activity and seedling establishment were significantly reduced due to the changes in the water level fluctuation pattern (Chen et al., 2019;Guan et al., 2020a; Guan et al., 2020b). This study further elucidated the effects of regulated water-level fluctuations on the formation and changes in $M$. laxiflora branch and leaf growth traits. The change of branch and leaf growth traits facilitate the remnant $M$. laxiflora populations to cope with environmental stress. However, generally the changes of branch and leaf growth traits are clearly unfavorable to the growth of plants distributed at the middle and lower regions of the fluctuation zone. Because $M$. laxiflora have extremely small leaves, their young branches (green-colored) are also important photosynthetic organs. A decrease in the number of branch and leaves will affect the photosynthetic capability and the accumulation of organic matters of plants (Guan et al., 2020b), which further influences the plant growth and sexual reproduction after flood (Chen et al., 2019: Guan et al., 2020a). This could explain why M. laxiflora populations continue to degenerate under the regulated water level fluctuation pattern (Bao et al., 2010).

\section{Conclusions}

The construction of the Three Gorges-Gezhou Dam alters the water level fluctuation pattern in the downstream habitat of the endangered species Myricaria laxiflora, which causes the emergence time of habitats delayed and the flooding retreat rapidly. We investigated the changes of $M$. laxiflora remnant populations in branch and leaf growth traits across water level condition during the growth restart period. The effect of environmental change on plant growth and plant adaptability to environmental changes were evaluated and analyzed. Due to such disturbance, branch and leaf growth traits of M. laxiflora populations exhibited significant differences across water level conditions. The branch and leaf traits of plants changed with decreasing water level toward to decreasing plant height, leaf number and the number of secondary branches, and increasing maximum water content of branch and leaves. The phenotypic plasticity of $M$. laxiflora plants in branch and leaf growth traits alleviates the impacts of human-regulated water level fluctuations. However, the above ground growth of $M$. laxiflora plants distributed at the middle and lower areas of the fluctuation zone is still negatively affected. To protect this endangered species, the current flow regulation by the large-scale hydropower station could be adjusted to move the reservoir retention time earlier. The habitat exposure time would be moved earlier, and the rate of water level decline would be reduced, to satisfy the needs for plant growth and development.

\section{Methods}

\section{Study site}


The field experimental site was the Yanzhiba $\left(111^{\circ} 19^{\prime} 26^{\prime \prime} \mathrm{E}, 30^{\circ} 38^{\prime} 57^{\prime \prime} \mathrm{N}\right)$, an island located downstream of the Three Gorges-Gezhou Dam cascade hydropower station on the Yichang section along the Yangtze River mainstream. Approximately 10,000 M. laxiflora plants are distributed at this habitat, which is a relatively large remnant population according to available reports (Chen and Wang, 2015). This distribution site has humid subtropical climate with an annual average temperature of $16.9^{\circ} \mathrm{C}$, extreme maximum temperature $41.4^{\circ} \mathrm{C}$, extreme minimum temperature of $-9.0^{\circ} \mathrm{C}$, annual average precipitation of $1164.1 \mathrm{~mm}$. The site has sandy soil. Common vegetation on the river beach is shrubs dominated by $M$. laxiflora and Salix variegata communities.

Due to the typical seasonal water-level fluctuations in the Yangtze River, M. laxiflora remnant populations are submerged by flooding between June-August every year. From September to May of the following year when water level is relatively low, M. laxiflora emerges and grows. Based on the characteristics in the submergence and emergence at different altitudes of the habitat, we divided the research area into three water level conditions: upper region (altitude (above the sea level) $\geq 45.1 \mathrm{~m}$ ), middle region (altitude $45.1 \mathrm{~m}-42.8 \mathrm{~m}$ ), and lower region (altitude $\leq 42.8 \mathrm{~m}$ ) (Chen et al., 2019). A sample transect was established at each water-level condition. In each sample transect, a $5 \mathrm{~m} \times 5 \mathrm{~m}$ quadrat was set up every $10 \mathrm{~m}$, with a total of 10 quadrats for measuring changes in branch and leaf traits of $M$. laxiflora in each elevational belt during growth recovery.

\section{Measurements of branch and leaf traits}

On Days 10, 20, 30, 40, and 50 after plant emergence, one $M$. laxiflora plant with uniform size was selected from each quadrat for the investigation of branch and leaf growth traits. We measured the following six parameters: plant height, number of secondary branches, the longest secondary branch length, leaf number, branch and leaf volume, and branch and leaf water content (Xiang et al., 2019; Li et al., 2018 ).

Plant height was measured using a measuring tape, from the green leaf on top of the plant to the base. The number of secondary branches, leaf number, and the longest secondary branch length were obtained by randomly selecting a primary branch from each sample plant, counting the number of secondary branches grown from the first branch, and measuring the length of the longest secondary branch. Then, three secondary branches were randomly selected from each sample branch, from which leaf number was determined. In each water-level fluctuating region at each time point since growth restart, 30 secondary branches were measured. The $M$. laxiflora secondary branches used in the measurements were harvested, placed on ice, and transferred to the laboratory for the measurements of branch and leaf volume, and branch and leaf water content. The branches harvested were placed in water and kept in dark at $5{ }^{\circ} \mathrm{C}$ for $12 \mathrm{~h}$. Then branches were taken out of the water and blotted using filter paper. The fresh weight of the branches was measured on an electronic balance ( 0.0001 accuracy). Then, the branches were placed in a burette (accuracy $0.01 \mathrm{~mL}$ ) to determine branch and leaf volume. Finally, the branches were placed at $105^{\circ} \mathrm{C}$ for $15 \mathrm{~min}$ for enzyme deactivation, and dried at $60^{\circ} \mathrm{C}$ to a constant weight. Branch and leaf dry weight was recorded and used to calculate the maximum water content of branch and leaf using the following equation: Maximum branch and leaf water content $=$ (Branch and leaf fresh 
weight - Branch and leaf dry weight) / Branch and leaf fresh weight $\times 100 \%$ (Pérez-Harguindeguy et al., 2013).

\section{Measurements of the aquatic ecological environment}

From the exposure of the habitat, water level information at the test site was monitored and recorded every day (using the water level of Yangtze River at Yichang section as a reference, published at http://www.cjh.com.cn). Based on our on-site investigation, combining the altitude changes of the Yangtze River water level, we analyzed the water level changes at each sample transect and the emergence status (Fig. 1). The upper water level-fluctuating region was emerged on September 8, 2018; the middle and lower regions emerged on September 16, 2018 and November 3, 2018, respectively. During this period, from September 16 to October 14, 2018, due to the rising of water level in the Yangtze River, plants in the middle region were submerged twice. In comparison with that before the dam was built, the emergence time of the habitat under human regulation was postponed for nearly two months.

Concurrently with branch collections, soil water content was also measured. Three locations were randomly selected in each quadrat of each sample transect; soil samples were collected using a cutting ring (15-cm depth) and transferred to the laboratory. The fresh weight and dry weight of soil were weighed to calculate soil water content. Thirty soil samples were collected at each sample transect.

\section{Statistical analysis}

After In-transformation of data and means were compared with LSD test, one-way ANOVA and multiple comparisons (post hoc Tukey) were performed by setting water level condition as independent variable, and branch and leaf growth traits as dependent variables. The significance of differences among treatments for each parameter and the pattern of how branch and leaf growth traits varied across water level conditions were examined and analyzed respectively. Pearson correlation analysis was conducted to analyze and test the correlation between $M$. laxiflora branch and leaf growth traits and soil water content. Principal component analysis (PCA) of branch and leaf growth traits was conducted to assess the effects of the regulated water level fluctuations on the branch and leaf functional symptoms, and reveal the response of $M$. laxiflora remnant populations in growth to the regulated water level fluctuations. All data analyses were performed using SPSS 19.0.

\section{Abbreviations}

$\mathrm{PH}$, Plant height; NB, Number of secondary branches; LB, Longest secondary branch length; LN, Leaf number; BV, Branch leaf volume; BWC, Maximum branch leaf water content

\section{Declarations}


Acknowledgments

The authors thank Y. Ma, X. Tan and D. Xiong, who helped with field work and laboratory experiment.

\section{Authors'contributions}

SG, FC and DF developed the concept of the manuscript. SG and JZ collected the data in the field. SG, DF and YL contributed to statistics and graphics. All authors contributed to the text writing.

\section{Funding}

The financial support granted by the National Natural Science Foundation of China (31770564) and the National Key Research and Development Program of China (2017YFC0504904) is gratefully acknowledged.

\section{Availability of data and materials}

The datasets generated during this study are available from the corresponding author on reasonable request.

\section{Conflict of interest:}

The authors declare that they have no conflict of interest. This articles does not contain any studies with human participants or animals performed by any of the authors.

\section{Ethics approval and consent to participate}

The study complied with the Convention on International Trade in Endangered Species of Wild Fauna and Flora (CITES).

\section{Consent for publication}

Not applicable.

\section{Competing interests}

The authors declare that they have no competing interests.

\section{Author details}

1 Hubei International Scientific and Technological Center of Ecological Conservation and Management in the Three Gorges Area, China Three Gorges University, Yichang, Hubei Province, P. R. China; 2 College of Forestry, Beijing Forestry University, Beijing, P. R. China, 100083

\section{References}


Bao DC, Lu ZJ, Jiang MX, Xu SD, Yao Q, Liu QF, Wang Q. Population structure and dynamics of remanent Myricaria laxiflora downstream from the Three Gorges Dam. J Wuhan Bot Res. 2010; 28:711-717.

Bernard-Verdier M, Navas ML, Vellend M, Violle C, Garnier E. Community assembly along a soil depth gradient: contrasting patterns of plant trait convergence and divergence in a mediterranean rangeland. $J$ Ecol. 2012; 100:1422-1433.

Bijarchi R, Sohrabi M R, Juibari MY, Yoonessi A. The ecology, effect of dams, and restoration of the black cottonwood (Populus trichocarpa T. \& G.) forest community in the intermountain west. Dissertat Theses Gradworks. 2011; 2:1-7.

Blom CWHG, Voesenek L ACJ, Banga M, Engelaar WMHG, Rijnders JHGM, van Steeg HM, Visserl EJW. (1994). Physiological ecology of riverside species: adaptive response of plants to submergence. Ann Bot. 74:253-263.

Bradshaw AD. Unravelling phenotypic plasticity $\llbracket$ why should we bother? New Phytol. 2006; 170:644 -648 .

Campbell D, Keddy PA, Broussard M, Mcfalls-Smith TB. Small changes in flooding have large consequences: experimental data from ten wetland plants. Wetlands. 2016; 36:457-466.

Chen FQ, Xie ZQ. Reproductive allocation, seed dispersal and germination of Myricaria laxiflora, an endangered species in the Three Gorges Reservoir area. Plant Ecol. 2007; 191: 67-75.

Chen FQ, Wang $\mathrm{CH}$. Ecological protection of the rare and endangered plant Myricaria laxiflora in the Three Gorges Area. Beijing. 2015; Science Press.

Chen FQ, Xie ZQ. Survival and growth responses of Myricaria laxiflora seedlings to summer flooding. Aquat Bot. 2009; 90:333-338.

Chen FQ, Guan SP, Ma Y R, Xie ZQ, Lv K, Huang YW, Jia GM. Impact of regulated water level fluctuations on the sexual reproduction of remnant Myricaria laxiflora populations. Glob Ecol Conserv. 2019; 18:e00628.

Chen FQ, Xie ZQ, Xiong GM, Liu YM, Yang HY. Reintroduction and population reconstruction of an endangered plant Myricaria laxiflorain the Three Gorges Reservoir area, China. Acta Ecol Sin. 2005; 25:1811-1817.

Chen FQ, Huang YZ, Zeng X. Biological response of Cynodon dactylon vegetative propagule to simulated flooding. J Trop Subtrop Bot. 2010; 18:15-20. (in Chinese with English abstract)

Collins CG, Wright SJ, Wurzburger N. Root and leaf traits reflect distinct resource acquisition strategies in tropical lianas and trees. Oecologia. 2016; 180:1037-1047. 
Dalke IV, Novakovskiy AB, Maslova SP, Dubrovskiy YA. Morphological and functional traits of herbaceous plants with different functional types in the European Northeast. Plant Ecol. 2018; 11:1295-1305.

Duan WX, Guo SL, Wang J. Impact of upper Yangtze River large-scale cascade reservoirs on flow regime at Yichang station. Resour Environ Yangtze Basin 2016; 25:120-130. (in Chinese with English abstract)

Duan YY, Song LJ, Niu SQ, Huang T, Yang GH, Hao WF. Variation in leaf functional traits of different-aged Robinia pseudoacacia communities and relationships with soil nutrients. Chin J Appl Ecol. 2017; 28: 2836. (in Chinese with English abstract)

Ellers J, Stuefer JF. Frontiers in phenotypic plasticity research: new questions about mechanisms, induced responses and ecological impacts. Evol Ecol. 2010; 24: 523-526区

Gao T, Chen M, Dang CQ, Huang HM, Dong R, Tao JP. Functional traits of major herbaceous plants in the hydro-fluctuation belt of the Three Gorges Reservoir. Pratacultural Sci. 2017; 32:2493-2503.

Gleason SM, Stephens AEA, Tozer WC, Blackman CJ, Butler DW, Chang Y, Cook AM, Cooke J, Laws CA, Rosell JA,Stuart SA, Westoby M. Shoot growth of woody trees and shrubs is predicted by maximum plant height and associated traits. Funct Ecol. 2017; 32:247-259.

Guan SP, Chen FQ, Lv K, Zhou JM, Huang YW. Effects of soil water conditions on seedling regeneration in Myricaria laxiflora remnant populations. Ecol Res. 2020a; 35:524-532.

Guan SP, Chen FQ, Zhou JM, Xie ZQ, Hunag YW. Spatiotemporal photosynthetic physiology responses of remnant Myricaria laxiflora populations to regulated water level fluctuations. Conserv Physiol. 2020b;

8:coaa020

Lajoie G, Vellend M. Characterizing the contribution of plasticity and genetic differentiation to community-level trait responses to environmental change. Ecol Evol. 2018; 8:3895-3907.

Lawson JR, Fryirs KA, Lenz T, Leishman MR. Heterogeneous flows foster heterogeneous assemblages: relationships between functional diversity and hydrological heterogeneity in riparian plant communities. Freshwater Biol. 2015; 60:2208-2225.

Li W, Zhou H, Fu A, Chen Y. Ecological response and hydrological mechanism of desert riparian forest in inland river, northwest of China. Ecohydrology. 2013; 6:949-955.

Li ZJ, Fan DY, Chen FQ, Xie ZQ. Physiological integration enhanced the tolerance of Cynodon dactylon to flooding. Plant Biol. 2015; 17:459-465.

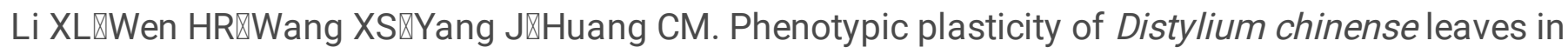
relation to soil environmental factors in heterogeneous habitats in the Three Gorges Reservoir Region. Acta Ecol Sin. 2018; 38: 3581-3591】 
Liu Z, Jiang F, Li F, Jin G. Coordination of intra and inter-species leaf traits according to leaf phenology and plant age for three temperate broadleaf species with different shade tolerances. Forest Ecol Manag. 2019; 434:63-75.

Matthew H, Gregg S, John WD, Robert VR, Andrew N, Robert L, Leigh AS. Drivers and impacts of water level fluctuations in the Mississippi River delta: Implications for delta restoration. Estuar Coast Shelf S. 2019; 224:117-137.

McCoy-Sulentic ME, Kolb TE, Merritt DM, Palmquist EC, Ralston BE, Sarr DA. Variation in specieslevel plant functional traits over wetland indicator status categories. Ecol Evol. 2017; 7:3732-3744.

Miao LF, Yang F, Han C, Pu YJ, Ding Y, Zhang LJ. Sex-specific responses to winter flooding, spring waterlogging and post-flooding recovery in Populus deltoides. Sci Rep. 2017; 7:2534.

Miles EM, Thomas EK, David MM, Emily P, Barbara ER, Daniel AS, Patrick BS. Changes in community-level riparian plant traits over inundation gradients, Colorado river, grand canyon. Wetlands. 2017; 37:635-646.

Munguia-Rosas MA, Angulo DF, Arceo-Gomez G. Variation in leaf traits across a precipitation gradient in coastal sand dunes in Yucatan Peninsula. J Arid Environ. 2019; 162:10-17.

Pérez-Harguindeguy N, Díaz S, Garnier E, Lavorel S, Poorter H, Jaureguiberry P, Bret-Harte MS, Cornwell WK, Craine JM, Gurvich DE. New handbook for standardised measurement of plant functional traits worldwide. Aust J Bot. 2013; 61:167-243.

Roderick ML, Berry SL, Noble IR, Farquhar GD. A theoretical approach to linking the composition and morphology with the function of leaves. Funct Ecol. 1999; 13:683-695.

Reich PB. The world-wide'fast-slow'plant economics spectrum: A traits manifesto. J Ecol. 2014; 102: 275301.

Spencer DF, Ksander GG, Whitehand LC. Spatial and temporal variation in RGR and leaf quality of a clonal riparian plant: Arundo donax. Aquat Bot. 2004; 81:27-36.

Sun SH, Li YT, Li M, Ge H. Effect of channel degradation on lower level in Yichang-Shashi reach in the Yangtze River. Hydro-Science and Engineering, 2007; (4):14-20. (in Chinese with English abstract)

Sultan SE. An emerging focus on plant ecological development. New Phytol. 2005; 166:1-5 .

Sultan SE. Phenotypic plasticity and plant adaptation. Plant Biol. 1995; 44:363-383区

Smaoui A, Jouini J, Rabhi M, Bouzaien G, Albouchi A, Abdelly C. Physiological and anatomical adaptations induced by flooding in Cotula coronopifolia. Acta Biol Hunga. 2011; 62:182-193.

Xiang L, Chen FQ, Geng MY, Wang YB, Lv K, Yang SL. Response of leaf functional traits of shrubs to altitude in Rhododendron latoucheae communities in Mt. Jinggangshan, Jiangxi, China. J Trop Subtrop 
Bot. 2019. 27:129-138. (in Chinese with English abstract)

Van der Sman AJ, Van Tonger OF. Growth and reproduction of Rumex maritimusand, Chenopodium rubrum under different waterlogging regimes, Acta Bot Neerl. 1988; 37: 439-450

Violle C, Navas ML, Vile D, Kazakou E, Fortunel C, Hummel I, Garnier E. Let the concept of trait be functional. Oikos. 2007; 116:882-892.

Voesenek LACJ, Bailey-Serres J. Flood adaptive traits and processes: an overview. New phytol. 2015; 206:57-73

Wang YJ, Chen FQ, Zhang M, Chen SH, Tan XQ, Liu M, Hu ZH. The effects of the reverse seasonal flooding on soil texture within the hydro-fluctuation belt in the Three Gorges reservoir, China. J Soil Sediment. 2018; 18:109-115.

Zhou TY, Gao J, He JD, Xue JY, Sun J, Wang J N, Xu B, Xie Y, Wu Y. Plant height, leaf traits, and biomass allocation of three species at heterogeneous slope aspects along a transect in an alpine meadow. Chin $\mathrm{J}$ Appl Environ Biol. 2018; 24:425-433. (in Chinese with English abstract)

\section{Figures}

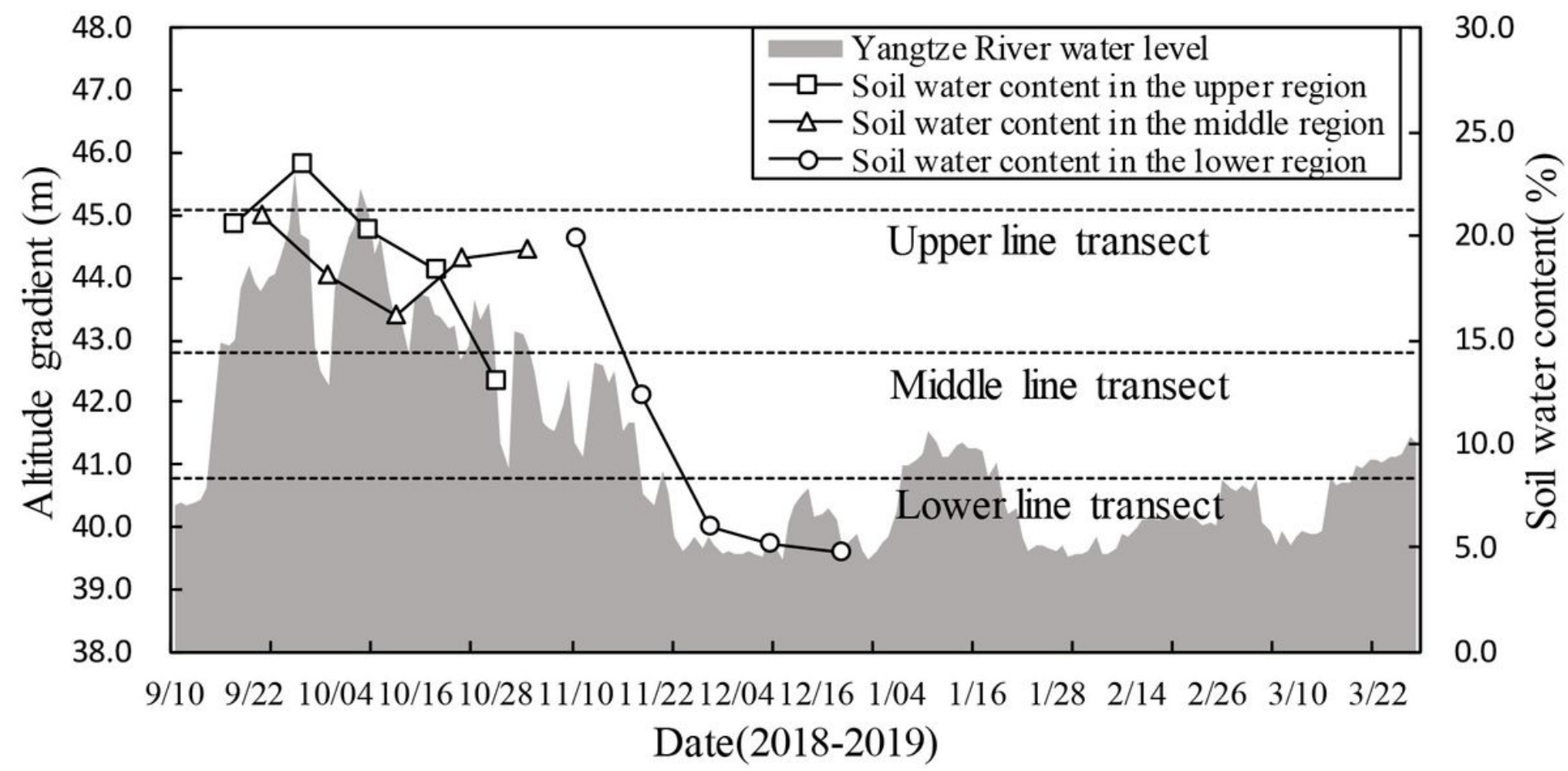

\section{Figure 1}

Water level fluctuations and changes in soil water content across water level conditions within the sample plot at the Yichang section of the Yangtze River 

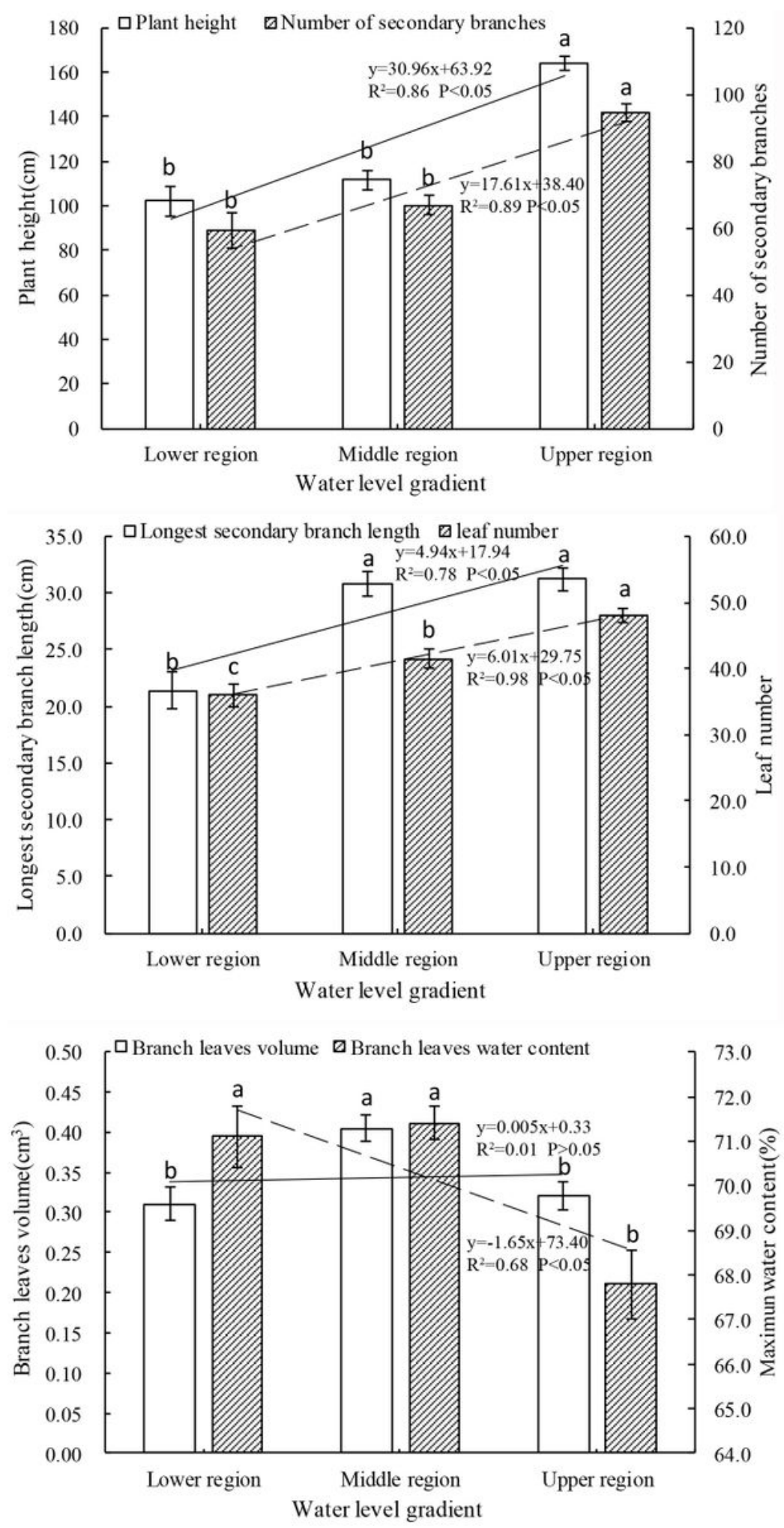

Figure 2

Changes of M. laxiflora plants in plant branch and leaf traits across water level conditions $(n=50)$ 


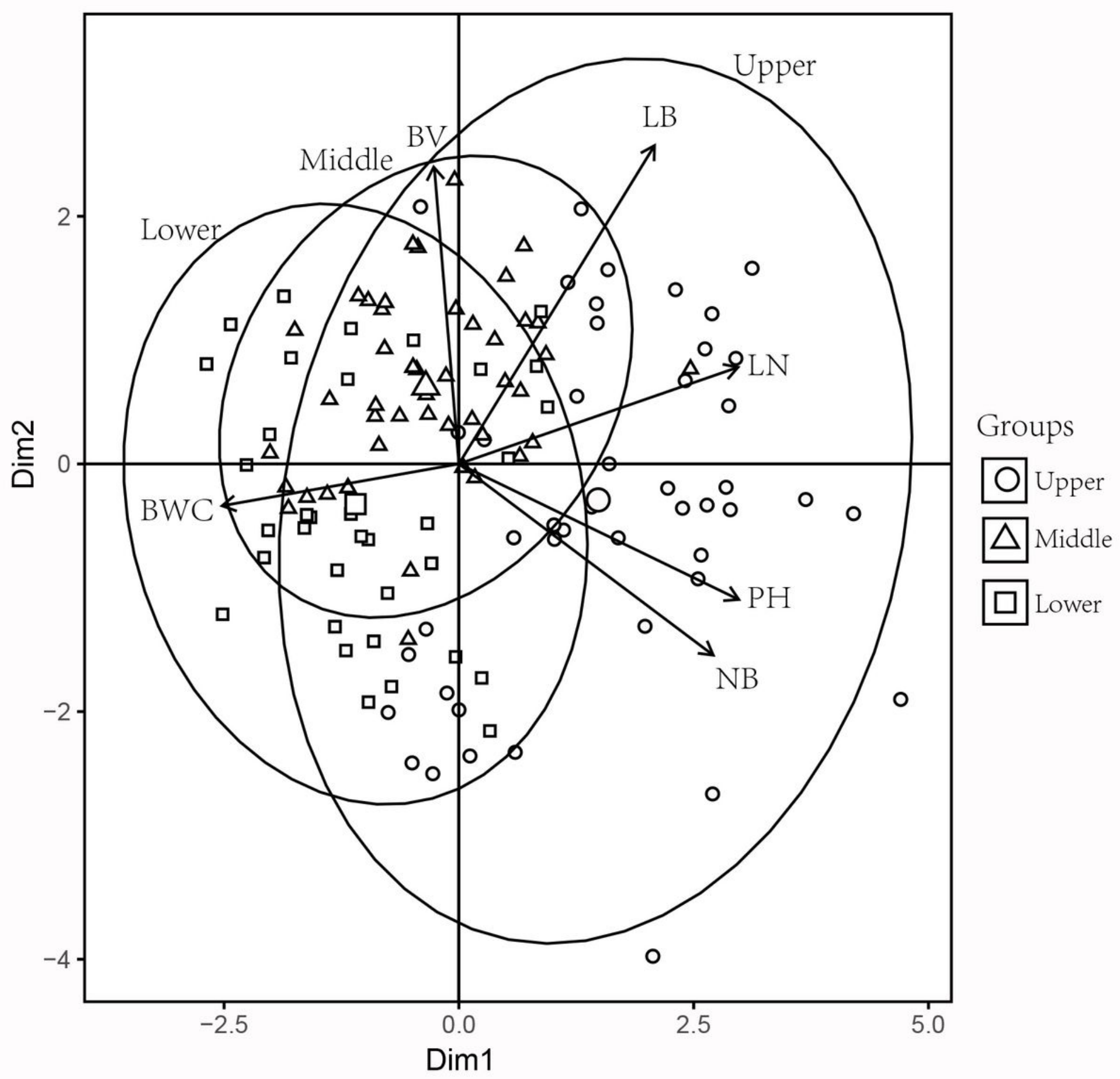

Figure 3

PCA ordination of M. laxiflora branch growth traits across water level conditions Note: PH, Plant height; NB, Number of secondary branches; LB, Longest secondary branch length; LN, Leaf number; BV, Branch leaf volume; BWC, Maximum branch leaf water content; The ellipse confidence interval level in the figure is 0.80 . 